\title{
Cystic fibrosis transmembrane conductance regulator (CFTR) regulates embryonic organizer formation during zebrafish early embryogenesis
}

\author{
YANYAN LIU1 ${ }^{1}$, ZIYUAN LIN² and HUAQIN SUN*,2 \\ ${ }^{1}$ Prenatal Diagnosis Center, Department of Obstetrics \& Gynecologic, and ${ }^{2}$ SCU-CUHK Joint Laboratory for Reproductive \\ Medicine, Key Laboratory of Birth Defects and Related Diseases of Women and Children, Ministry of Education, Department \\ of Pediatrics, West China Second University Hospital, Sichuan University, Chengdu, People's Republic of China
}

\begin{abstract}
Cystic fibrosis (CF) is associated with the manifestation of a number of medical conditions throughout the body. This prompted us to investigate the etiology of CF from the viewpoint of the embryonic organizer, which is responsible for steering the movement of surrounding cells into specific organs and tissues. In our previous work, we found that a cftr mutant had decreased nuclear $\beta$-catenin levels in the early embryo at 5 hours post-fertilization (hpf), when the organizer forms. It is known that nuclear $\beta$-catenin signaling is essential for the induction of the dorsal organizer. Therefore, we explored the role of $\mathrm{ctr}$ in the formation of the embryonic organizer in this work. Indeed, the expression of organizer and germ layer markers was significantly affected in cftr mutant embryos dependent on Wnt/ $\beta$-catenin signaling. Furthermore, quantitative proteome analysis revealed that the cftr mutant induced significant alteration in the expression of proteins related to many critical biological processes, cellular components, molecular functions, and signaling pathways, except for the Wnt/ $\beta$-catenin pathway. These findings demonstrate the function of cftr in embryonic organizer formation and provide an explanation for why many abnormalities occur in the bodies of CF patients.
\end{abstract}

KEY WORDS: CFTR, organizer, early embryogenesis

\section{Introduction}

Cystic fibrosis transmembrane conductance regulator (CFTR) is a cAMP-activated anion channel protein that belongs to ATPbinding cassette $(\mathrm{ABC})$ transporter superfamily (Gadsby et al., 2006). It was first found to be expressed in a wide variety of epithelial tissues (Tizzano et al., 1993). Mutations of CFTR cause cystic fibrosis (CF), the most common lethal congenital disease in Caucasians (Quinton, 1999, Riordan, 2008). The hallmark of CF is a defect in electrolyte and fluid transport affecting multiple organ systems with a multitude of clinical manifestations (Quinton, 1999, Riordan, 2008), such as obstructive lung disease (Johannesson et al., 2012, Pezzulo et al., 2012), pancreas exocrine deficiency (Wilschanski and Novak, 2013), CF-related diabetes (Guo et al., 2014), and abnormal gonad function and infertility (Chen et al., 2012, Lu et al., 2012, Xu et al., 2007), which is characterized by progressive organ dysfunction with the development of scarring and fibrosis (Bright-Thomas and Webb, 2002, Labombarda et al., 2016).

Organizers, which comprise groups of cells with the ability to instruct adjacent cells into specific states, represent a key principle in developmental biology. In the context of an embryo, an 'organizer' refers to a group of cells that harbor the ability to instruct fates and morphogenesis in surrounding cells, steering their development into specific organs and tissues. As a result, organizers can position specific tissues and organs relative to each other (Martinez Arias and Steventon, 2018). Therefore, CF patients encountering various additional health issues inspired us to investigate the etiology from the viewpoint of embryonic organizer.

Importantly, in our previous work, we showed that defective cftr results in accelerated Dpr1 induced Dvl2 degradation, and thus nuclear $\beta$-catenin expression reduction, leading to inactivation

Abbreviations used in this paper: CF, cystic fibrosis; CFTR cystic fibrosis transmembrane conductance regulator.

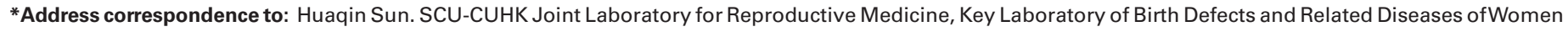

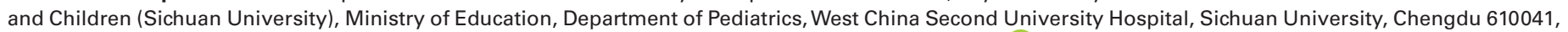
People's Republic of China. E-mail: sunhuaqin@scu.edu.cn - Web: https://zfin.org/ZDB-PERS-181113-1 - (iD) https://orcid.org/0000-0002-4548-4657
} 
of Wht signaling at the beginning of gastrula period ( $5 \mathrm{hpf}$ ) and impaired hematopoiesis during zebrafish early embryogenesis (Sun et al., 2018). $\beta$-catenin is the key effector of canonical Wnt signals in the future dorsal blastomeres and it induces the formation of the organizer, which acts as a signaling center for correct embryonic patterning and gastrulation cell movements (Yan et al., 2018). So, we ask whether CFTR regulates embryonic organizer formation during early embryogenesis.

In this study, we used a zebrafish cftrmutant model established by us to investigate the function of cftrin organizer formation during embryo development. Our results showed that the formation of embryonic organizer and germ layers was impaired in cftrmutant embryos, suggesting an important role of cftr in early embryogenesis and providing an explanation for the multitude of clinical manifestations that occur throughout the body in CF patients.

\section{Results}

\section{Dorsal organizer formation and early embryogenesis are impaired in cftr mutant embryos}

In our previous work, we showed that cftr deficiency caused by the mutation or knockdown of this gene results in reduced nuclear $\beta$-catenin expression induced by $\mathrm{Dvl} 2$ degradation at the beginning of gastrula period (5hpf) (Sun et al., 2018). Stage of $50 \%$ epiboly (5hpf) is not only the starting time of the zebrafish gastrula period to produce mesoderm and hematopoietic progenitors, but also the key time to induce the formation of embryonic organizer (Thisse and Thisse, 2015).

To determine whether cftr plays an important role in organizer development during zebrafish embryogenesis, we continued to perform analysis on our existing cftrmutant zebrafish lines cftrccu102
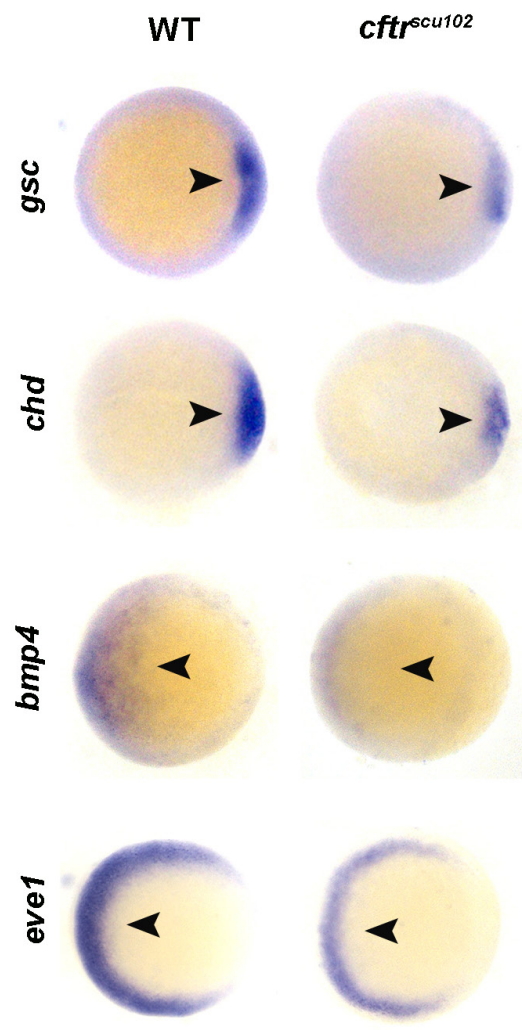
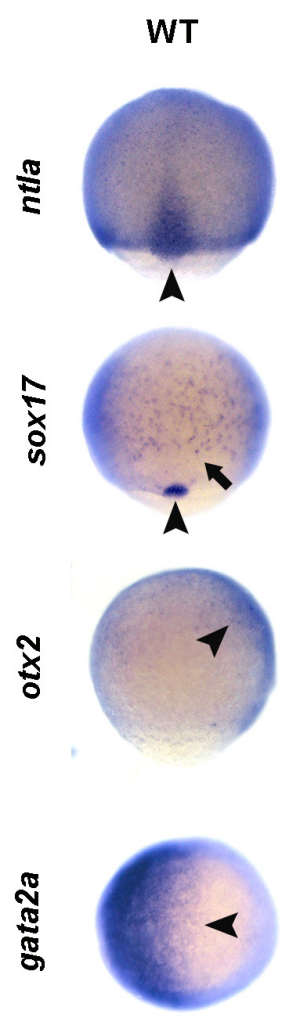

(http://zfin.org/action/feature/view/ZDB-ALT-190307-1). cftrcu102 carried a 2-bp deletion in Exon 6, causing a frameshift mutation leading to a premature stop codon at 219 AA (Sun et al., 2018).

As revealed by whole-mount in situ hybridization (WISH), the dorsal organizer markers $g s c$ and $c h d$ are reduced significantly in cftrsu102 mutants at the shield stage. Meanwhile, the ventral markers bmp4 and eve1 and the epidermis marker gata2a also showed decreased expression in mutants at this stage. Furthermore, similarly to the marker genes detected at the shield stage, the mesodermal marker gene $n t l a$, the endodermal marker gene sox17, and the anterior neuroectoderm marker gene otx2 were expressed at lower levels at the $70 \%$ epiboly stage. Notably, both endoderm (indicated with arrow) and forerunner cell group (indicated with arrowhead) marked by sox17 showed reduced expression pattern in cftrcu102 mutant (Fig. 1).

Interestingly, expression of the myogenic marker myod was also reduced in mutants at $24 \mathrm{hpf}$, however, the notochord mesodermal marker ntla and the central nervous system marker sox3 did not show any obvious changes (Fig. 2). These data suggest that in the absence of $c f t r$, the development of early embryos is impaired.

\section{Cftr function on embryonic organizer is dependent on Wnt/ $\beta$ - catenin signaling}

Given that Cftr deficiency impairs Wnt/ $\beta$-catenin signaling and hematopoiesis in our previous work(Sun et al., 2018), we investigated the functional relationship between $\mathrm{Cftr}$ and $\mathrm{Wnt} / \beta$ catenin on organizer formation. Thus, it appears plausible that the impaired organizer in cftrmutant could be due to a deficiency in Wnt/ $\beta$-catenin. Indeed, injection with $d v / 2$ or $\beta$-catenin mRNA ameliorated the impaired organizer caused by deficient Cftr: embryos with normal gsc and chd expression pattern appeared in cftr mutant (Fig. 3). These data suggest that Cftr functions

\section{cftrocu102}

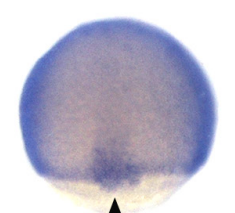

$\Lambda$
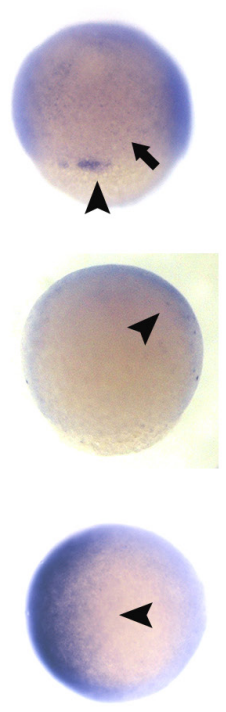
through Wnt/ $\beta$-catenin on organizer formation.

Proteomics analysis shows aberrant expression of proteins essential for embryo development in cftr mutant embryos at shield stage

Although the reduced nuclear $\beta$-catenin levels in cftrmutants could provide an explanation for why embryonic organizer formation was impaired, we still need to uncover the underlying molecular mechanism. So, we performed an integrated approach involving TMT labeling and LC-MS/MS to quantify the dynamic changes of the whole proteome of zebrafish embryos at shield stage (6 hpf) (cftrcu102 mutant vs WT).

In total, 3,381 proteins from embryos were identified in response to $\mathrm{cftr}^{\mathrm{ccu} 102}$ mutant and WT embryos, among which 2,836 proteins were quantified. All the annotation and quantification

Fig. 1. Embryonic organizer and germ layer marker expression detected by WISH during gastrulation. Orientation: ntla and sox17, dorsal views with animal pole to the top; otx2, side views with dorsal to the right at 70\% epiboly stage; others, top views (gsc, chd, bmp4, eve1 and gata2a) with dorsal to the right at shield stage. Arrowheads indicate the expression sites of each marker gene. 


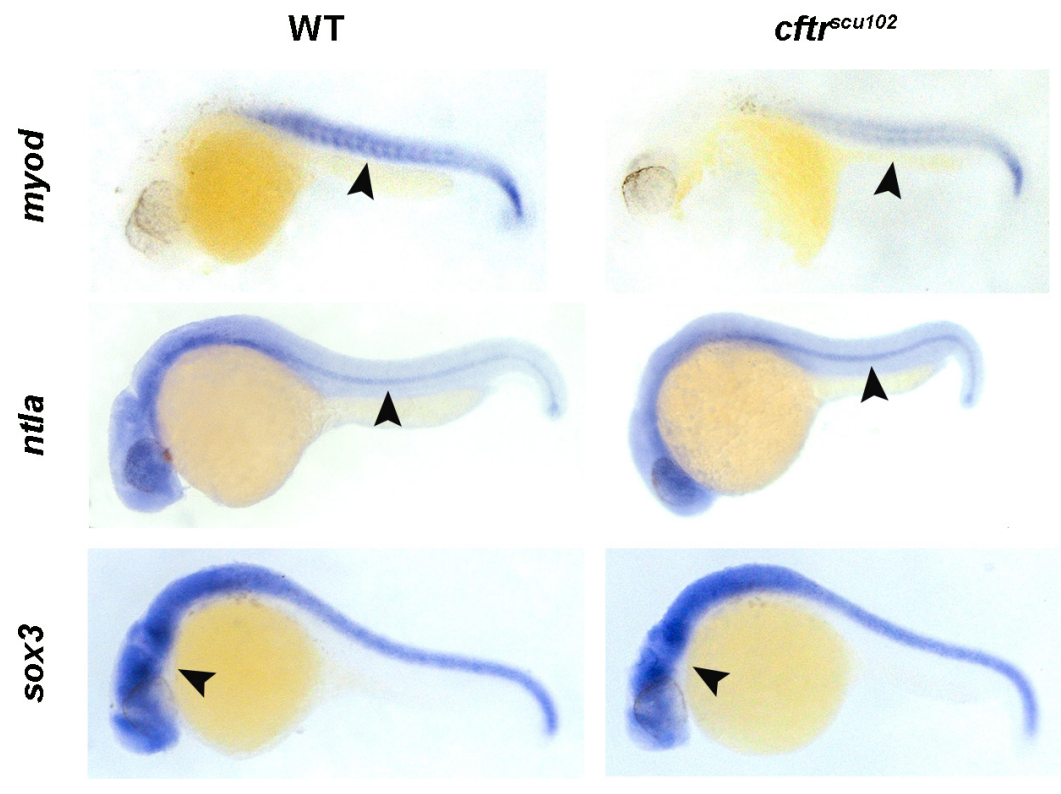

Fig. 2. Marker expression of $\mathbf{m y o d}$, ntla and sox 3 at $\mathbf{2 4}$ hpf. Lateral views with anterior to the left. Arrowheads indicate the expression sites of each marker gene.

information were presented in the Supplemental Table S1. Relative quantitation of proteins was divided into two categories. Quantitative ratio over 1.2 was considered up-regulation while quantitative ratio less than 1/1.2 was considered as down-regulation. Results showed that cftrcu102 mutant induced 190 differentially expressed proteins (117 up-regulated and 73 down-regulated) (Supplemental Table S2).

To characterize the function of these altered proteins, a Gene Ontology (GO)-based classification analysis of the ontology of biological processes, cellular components and molecular functions was performed, and it revealed widely different distributions between cftr $^{\text {su102 }}$ mutant and WT embryos (Fig. 4Aand Supplemental Table S3). With regard to biological processes, we discovered that the proteins in response to $\mathrm{cftr}^{\mathrm{scu} 102}$ mutant showed enrichment of cellular processes, single-organism processes, metabolic processes, biological regulation, developmental processes, multicellular organismal process, response to stimulus, cellular component

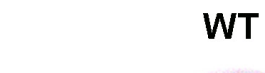

$\ddot{\leftrightarrow}$
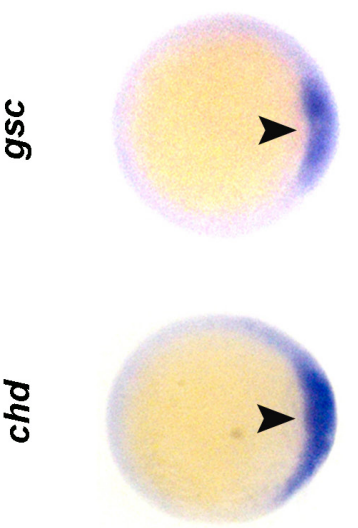
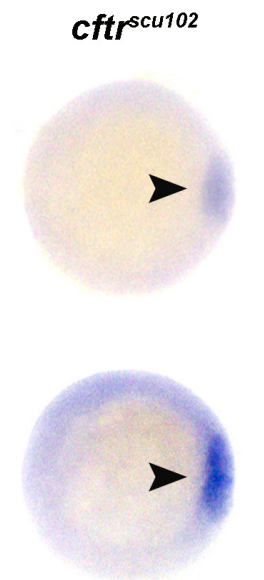
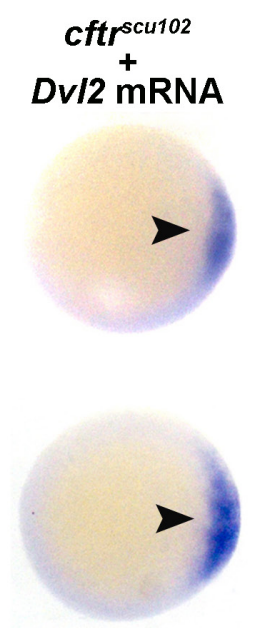

organization or biogenesis, localization, etc. Molecular function-based enrichment results revealed that binding, catalytic activity, molecular function regulators, structural molecule activity, transporter activity, etc. in regulated proteins were enriched in cftrcu102 mutant embryos. In the cellular component category, cytoplasm, extracellular, nucleus, mitochondria, plasma membrane, endoplasmic reticulum, cytoskeleton, etc. were enriched in the regulated proteins (Fig. 4B and Supplemental Table S4).

To further characterize the mechanism of these altered proteins, KEGG pathway-based classification analysis on the signaling pathways was performed, and it revealed a widely different distribution in ftr $^{\text {scu102 }}$ mutant embryos compared to WT, including metabolic pathways, biosynthesis of amino acids, glycolysis/ gluconeogenesis, amino sugar and nucleotide sugar metabolism, carbon metabolism, ECM-receptor interaction, pentose phosphate pathway, pentose and glucuronate interconversions, glutathione metabolism, fructose and mannose metabolism, AGE-RAGE signaling pathway in diabetic complications, fatty acid metabolism and metabolism of xenobiotics by cytochrome (Fig. 4C and Supplemental Table S5).

In conclusion, quantitative analysis of the global proteome between cftrscu102 mutant and WT embryos indicated that cftr mutation significantly impacts embryos, resulting in a remarkable alteration of many critical biological processes, celIular components, molecular functions and signaling pathways, except for the Wnt/B-catenin pathway.

\section{Discussion}

WISH detected both maternal and zygotic cftr expression throughout early development. This expression patterns suggest that cftr plays a role in early axis formation(Sun et al., 2018). Loss of cftr function in zebrafish model leads to destruction of the embryonic hematopoiesis (Sun et al., 2018), the migration of primordial germ cells (Liao et al., 2018), cardiac development (our submitted data), the organ laterality defects, the lumen expansion, function of Kupffer's vesicle (Navis et al., 2013), exocrine pancreas (Navis and Bagnat, 2015) and the gut tube (Bagnat et al., 2010). These cystic fibrosis phenotypes mirror the symptoms in the human disease.

While raising cftr mutants to adulthood, a large percentage of the mutants are lost beginning around 10 dpf (Liao et al., 2018). Furthermore, the cftr mutants begin to experience growth restriction coincident with the decreased survival (Navis and Bagnat, 2015), suggesting the impaired body development at early embryogenesis.

Fig. 3. Effects of $d v / 2$ or $\beta$-catenin mRNA in rescuing organizer defects in cftr mutant. Embryos shown are top views with dorsal to the right at shield stage. 
A

- Biological Process = Cellular Component $=$ Molecular Function
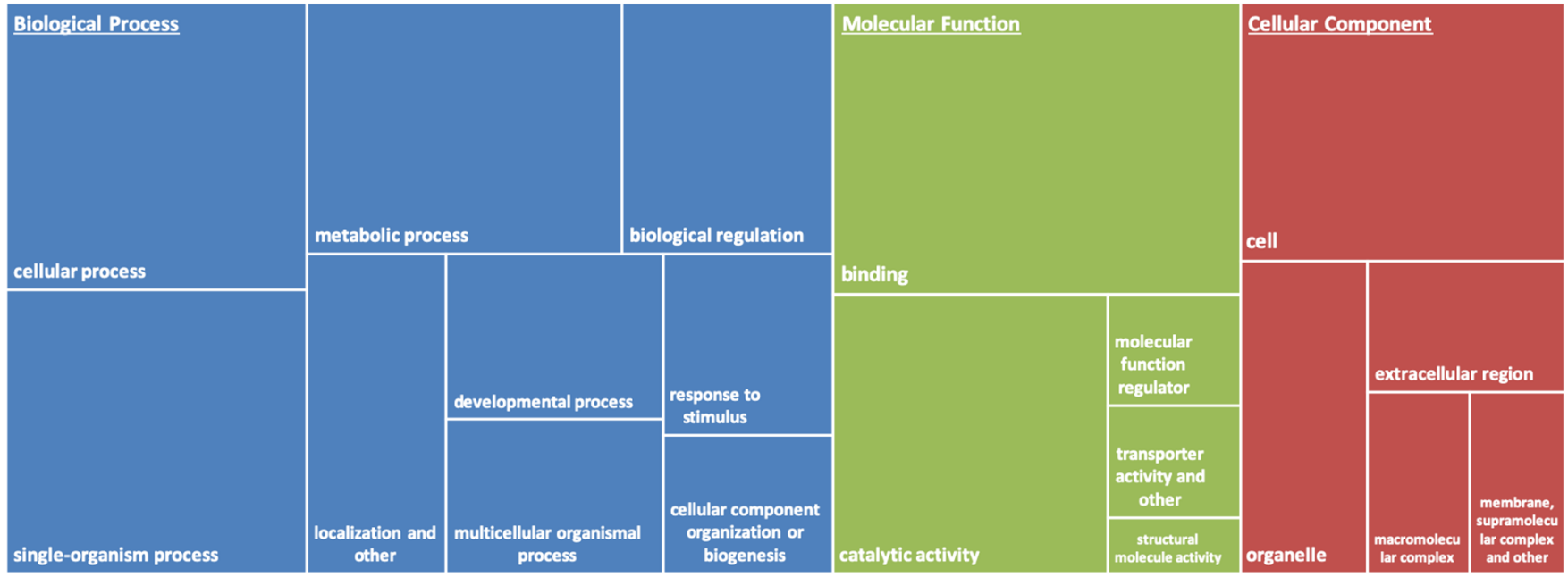

B

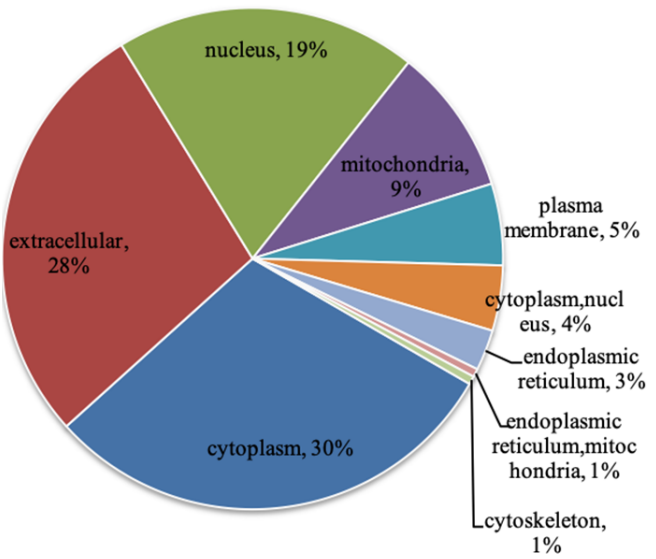

C

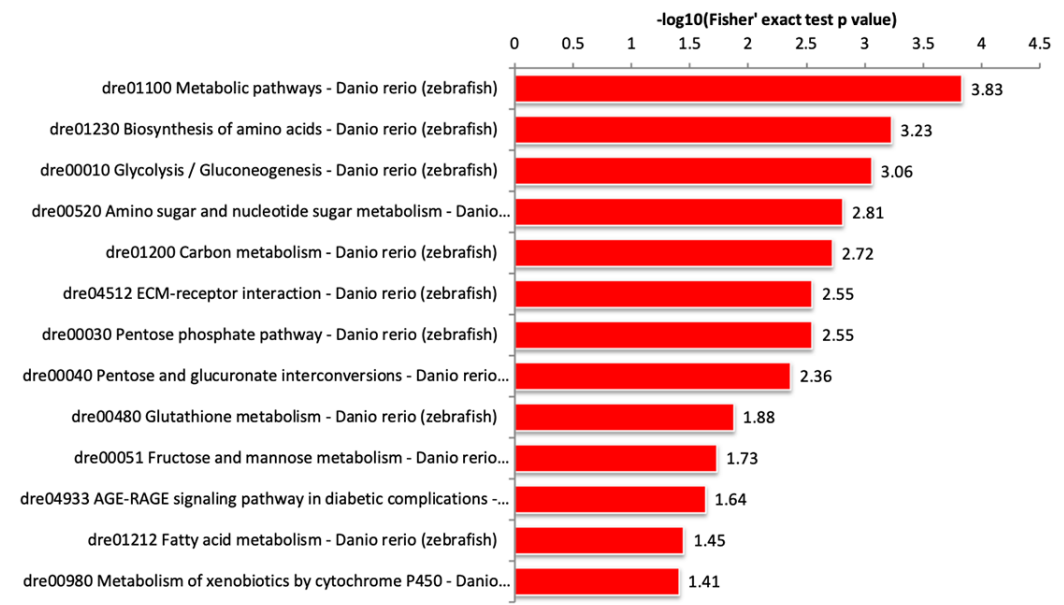

Fig. 4. The cftr mutant induces significant alterations in the proteome of embryos at the shield stage (cftreu102 mutant vs WT). (A) Gene Ontology (GO)-based enrichment analysis of regulated proteins on the ontology of biological processes, cellular components, and molecular functions. (B) Cellular component category analysis of regulated proteins. (C) KEGG pathway classification analysis of proteomic data.

Navis et al., described that proper midline expression of $n t /$ and lefty 1 indicates that midline integrity is not perturbed in their cftr mutants. In addition, the notochord and floorplate of their cftrmutants appeared to be completely intact at 24 hours post-fertilization (hpf) as judged by DIC microscopy (Navis et al., 2013). Consistently, we also observed that the midline, notochord and floorplate marked by $n t l a$ and sox3 were not impaired in embryos at $24 \mathrm{hpf}$.

Unfortunately, the identified quantitative proteins were fewer than expected in the embryonic proteomics analysis, because of high proportion of yolk proteins in early embryos. Even so, we identified 3,381 proteins and quantified 2,836 proteins and found 190 differentially expressed proteins. GO function classification analysis revealed that a wide range of proteins is regulated by cftrcu102 mutants, affecting many critical biological processes, cellular components, molecular functions, and signaling pathways except for the $\mathrm{Wnt} / \beta$-catenin pathway.

\section{Materials and Methods}

\section{Ethical approval and ethics statement}

All experiments in this study were in accordance with the "Guide for the Care and Use of Laboratory Animals" (Eighth Edition, 2011. ILARCLS, National Research Council, Washington, D.C.) and were approved by the Animal Care and Use Committee of West China Second University Hospital, Sichuan University (Approval ID: HXDEYY20131021).

\section{Zebrafish lines and embryos}

Wildtype (WT) AB strain, cftrcu102 (http://zfin.org/action/feature/view/ ZDB-ALT-190307-1) fish lines were utilized. Staging of the embryos was carried out as previously described (Sun et al., 2018).

\section{Proteomics analysis of embryos}

Quantitative proteome analysis was performed by PTM-Biolabs (HangZhou) Co., Ltd., detailed materials and methods was same to our 
previous work(Liu et al., 2017).

\section{Assays and statistics}

Zebrafish embryo whole-mount in situ hybridization, grayscale measurement, and statistics were performed as previously described(Sun et al., 2018).

\section{Declaration of interest}

All the authors listed declare no competing financial interests and have approved the manuscript that is enclosed.

\section{Availability of data and materials statements}

All data generated or analyzed during this study are included in this published article.

\section{Funding and Acknowledgements}

This research was supported by grants from the Sichuan Science and Technology Program (2017SZDZX0013 and 2019YFS0350), the NationalNatural Science Foundation of China (81200339), the China Postdoctoral Science Foundation (20110491723), the Young Teacher foundation of Sichuan University (2011SCU11040), the National Basic Research Program of China (2012CB944903) and the National 973 project (2013CB967404).

\section{Author Contributions statement}

H.S. and Y.L. conceived and designed the experiments; H.S. and Z.L. performed the experiments; H.S. and Y.L. analyzed the data; H.S. wrote the paper.

\section{References}

BAGNAT, M., NAVIS, A., HERBSTREITH, S., BRAND-ARZAMENDI, K., CURADO, S., GABRIEL, S., MOSTOV, K., HUISKEN, J. and STAINIER, D.Y. (2010). Cse1l is a negative regulator of CFTR-dependent fluid secretion. Curr Biol 20: 1840-1845.

BRIGHT-THOMAS, R.J. and WEBB, A.K. (2002). The heart in cystic fibrosis. $J R$ Soc Med 95 Suppl 41: 2-10.

CHEN, H., GUO, J.H., LU, Y.C., DING, G.L., YU, M.K., TSANG, L.L., FOK, K.L., LIU, X.M., ZHANG, X.H., CHUNG, Y.W. et al., (2012). Impaired CFTR-dependent amplification of $\mathrm{FSH}$-stimulated estrogen production in cystic fibrosis and PCOS. $J$ Clin Endocrinol Metab 97: 923-932.

GADSBY, D.C., VERGANI, P. and CSANADY, L. (2006). The ABC protein turned chloride channel whose failure causes cystic fibrosis. Nature 440: 477-483.

GUO, J.H., CHEN, H., RUAN, Y.C., ZHANG, X.L., ZHANG, X.H., FOK, K.L., TSANG, L.L., YU, M.K., HUANG, W.Q., SUN, X. et al., (2014). Glucose-induced electrical activities and insulin secretion in pancreatic islet beta-cells are modulated by CFTR. Nat Commun 5: 4420.

JOHANNESSON, B., HIRTZ, S., SCHATTERNY, J., SCHULTZ, C. and MALL, M.A.
(2012). CFTR regulates early pathogenesis of chronic obstructive lung disease in betaENaC-overexpressing mice. PLoS One 7: e44059.

LABOMBARDA, F., SALOUX, E., BROUARD, J., BERGOT, E. and MILLIEZ, P. (2016). Heart involvement in cystic fibrosis: A specific cystic fibrosis-related myocardial changes? Respir Med 118: 31-38.

LIAO, H., CHEN, Y., LI, Y., XUE, S., LIU, M., LIN, Z., LIU, Y., CHAN, H.C., ZHANG, $X$. and SUN, H. (2018). CFTR is required for the migration of primordial germ cells during zebrafish early embryogenesis. Reproduction 156: 261-268.

LIU, Y., LIN, Z., LIU, M., WANG, H. and SUN, H. (2017). Overexpression of DYRK1A a Down Syndrome Candidate gene, Impairs Primordial Germ Cells Maintenance and Migration in zebrafish. Sci Rep 7: 15313.

LU, Y.C., CHEN, H., FOK, K.L., TSANG, L.L., YU, M.K., ZHANG, X.H., CHEN, J., JIANG, X., CHUNG, Y.W., MA, A.C. et al., (2012). CFTR mediates bicarbonatedependent activation of miR-125b in preimplantation embryo development. Cell Res 22: 1453-1466.

MARTINEZ ARIAS, A. and STEVENTON, B. (2018). On the nature and function of organizers. Development 145:dev159525. doi: 10.1242/dev.159525.

NAVIS, A. and BAGNAT, M. (2015). Loss of cftr function leads to pancreatic destruction in larval zebrafish. Dev Biol 399: 237-248.

NAVIS, A., MARJORAM, L. and BAGNAT, M. (2013). Cftr controls lumen expansion and function of Kupffer's vesicle in zebrafish. Development 140: 1703-1712.

PEZZULO, A.A., TANG, X.X., HOEGGER, M.J., ALAIWA, M.H., RAMACHANDRAN S., MONINGER, T.O., KARP, P.H., WOHLFORD-LENANE, C.L., HAAGSMAN, H.P., VAN EIJK, M. et al., (2012). Reduced airway surface $\mathrm{pH}$ impairs bacterial killing in the porcine cystic fibrosis lung. Nature 487: 109-113.

QUINTON, P.M. (1999). Physiological basis of cystic fibrosis: a historical perspective. Physiol Rev 79: S3-S22.

RIORDAN, J.R. (2008). CFTR function and prospects for therapy. Annu Rev Biochem 77: 701-726.

SUN, H., WANG, Y., ZHANG, J., CHEN, Y., LIU, Y., LIN, Z., LIU, M., SHENG, K., LIAO, H., TSANG, K.S. et al., (2018). CFTR mutation enhances Dishevelled degradation and results in impairment of Wnt-dependent hematopoiesis. Cell Death Dis 9: 275 .

THISSE, B. and THISSE, C. (2015). Formation of the vertebrate embryo: Moving beyond the Spemann organizer. Semin Cell Dev Biol 42: 94-102.

TIZZANO, E.F., CHITAYAT, D. and BUCHWALD, M. (1993). Cell-specific localization of CFTR mRNA shows developmentally regulated expression in human feta tissues. Hum Mol Genet 2: 219-224.

WILSCHANSKI, M. and NOVAK, I. (2013). The cystic fibrosis of exocrine pancreas. Cold Spring Harb Perspect Med 3: a009746.

XU, W.M., SHI, Q.X., CHEN, W.Y., ZHOU, C.X., NI, Y., ROWLANDS, D.K., YI LIU, G., ZHU, H., MA, Z.G., WANG, X.F. et al., (2007). Cystic fibrosis transmembrane conductance regulator is vital to sperm fertilizing capacity and male fertility. Proc Natl Acad Sci USA 104: 9816-9821.

YAN, L., CHEN, J., ZHU, X., SUN, J., WU, X., SHEN, W., ZHANG, W., TAO, Q. and MENG, A. (2018). Maternal Huluwa dictates the embryonic body axis through beta-catenin in vertebrates. Science 362 
Further Related Reading, published previously in the Int. J. Dev. Biol.

Nodal signaling and the zebrafish organizer

A F Schier and W S Talbot

Int. J. Dev. Biol. (2001) 45: 289-297

http://www.intjdevbiol.com/web/paper/11291859

The avian organizer

T Boettger, H Knoetgen, L Wittler and M Kessel

Int. J. Dev. Biol. (2001) 45: 281-287

http://www.intjdevbiol.com/web/paper/11291858

The Spemann-Mangold organizer: the control of fate specification and morphogenetic rearrangements during gastrulation in Xenopus.

T Bouwmeester

Int. J. Dev. Biol. (2001) 45: 251-258

http://www.intjdevbiol.com/web/paper/11291854

Dickkopf1 and the Spemann-Mangold head organizer

C Niehrs, O Kazanskaya, W Wu and A Glinka

Int. J. Dev. Biol. (2001) 45: 237-240

http://www.intjdevbiol.com/web/paper/11291852

Molecular mechanisms of cell-cell signaling by the Spemann-Mangold organizer.

E M De Robertis, O Wessely, M Oelgeschläger, B Brizuela, E Pera, J Larraín, J Abreu and D Bachiller

Int. J. Dev. Biol. (2001) 45: 189-197

http://www.intjdevbiol.com/web/paper/11291846

Organizer and axes formation as a self-organizing process

$H$ Meinhardt

Int. J. Dev. Biol. (2001) 45: 177-188

http://www.intjdevbiol.com/web/paper/11291845
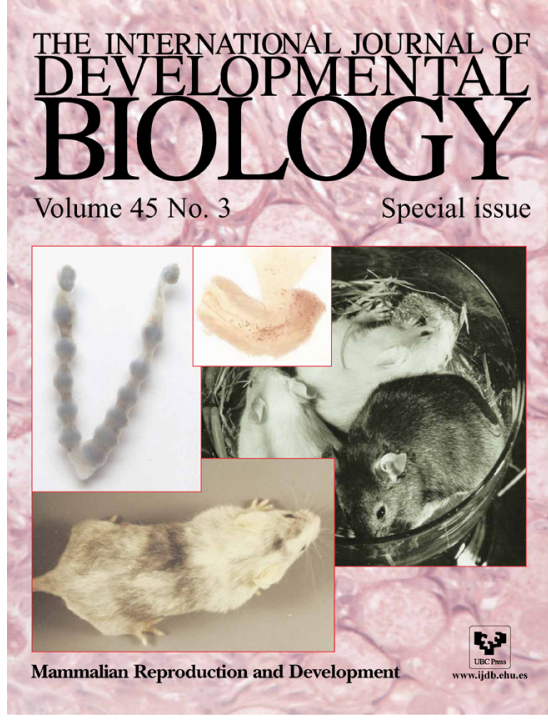

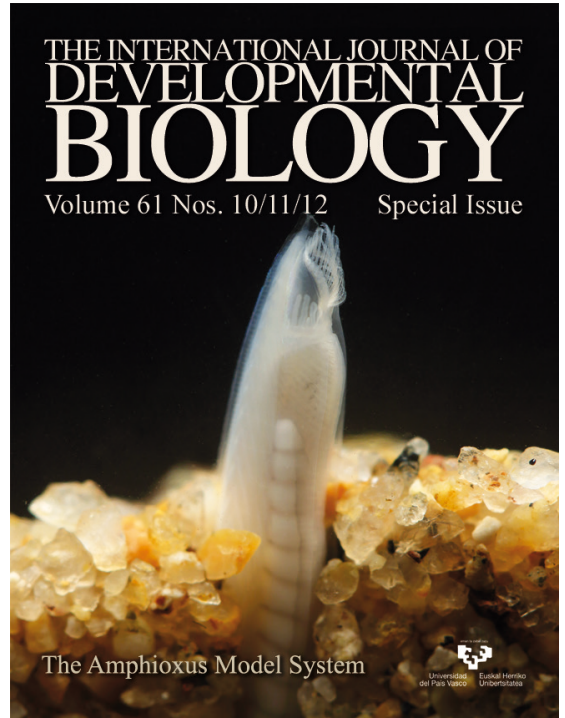

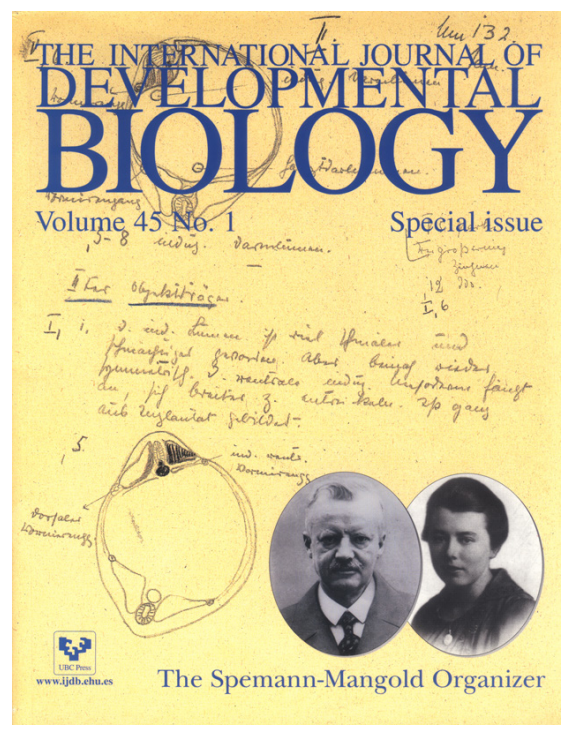

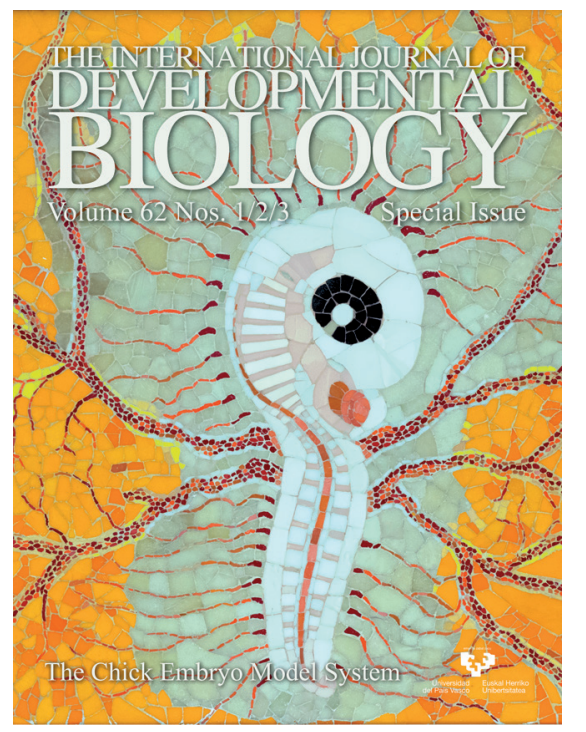

